\title{
La racionalidad instrumental como génesis de la conciencia tecnocrática ${ }^{1}$
}

\section{Instrumental rationality as genesis of technocratic consciousness}

Henry J. Escobar García²
Recibido: 18-feb-2019

Aceptado: 10-sep-2019

La inhumanidad está sepultada bajo la racionalidad mundana de la contabilidad.

(Marcuse, 1969, p. 19)

Cabría decir que el poder es siempre un poder potencial y no una intercambiable, mensurable y confiable entidad como la fuerza. [...] el poder surge entre los hombres cuando actúan juntos y desaparece en el momento en que se dispersan.

(Arendt, 1993/2016, p. 223)

\section{Resúmen}

Este artículo tiene una doble finalidad: en primer lugar, exponer la crítica que realizó H. Marcuse al concepto de racionalización de $\mathrm{M}$. Weber. Para ello, se muestra la manera en que la implantación de lo que él denomina conciencia tecnocrática conlleva un proceso gradual de despolitización de la sociedad; en segundo lugar, señalar precisiones conceptuales que establece J. Habermas sobre los procesos de racionalización, los cuales no necesariamente se reducen al cálculo de la razón instrumental y estratégica, pues pese a ello, hay un ingrediente de interacción social que posibilita lo que él denomina acción comunicativa que permite el entendimiento intersubjetivo, y por ende, el consenso político entre diversos actores sociales.

Palabras clave: racionalidad instrumental; conciencia tecnocrática; Habermas; Weber; trabajo.

\section{Abstract}

This paper has a double purpose: first, to expose the criticism conducted by $\mathrm{H}$. Marcuse to Max Weber's rationalization concept. In that sense, we show how the introduction of what he calls technocratic consciousness leads to a gradual process of society's depoliticization; secondly, to show the conceptual accuracy that sets J. Habermas about rationalization processes which do not necessarily reduce the calculation of instrumental and strategic reason, because despite this, there is an ingredient of social interaction that enables what he calls communicative action, which allows intersubjective understanding and thus, political consensus among various social actors.

Keywords: instrumental rationality; technocratic consciousness; Habermas; Weber; work.

\footnotetext{
1 El presente artículo es un producto del proyecto de investigación titulado "Conocimiento, ignorancia y acción", realizado en el grupo de investigación Yeshúa y financiado por la dirección de investigaciones de la Fundación Universitaria Católica Lumen Gentium.

2 Filósofo, magíster en Filosofía, candidato a Doctor en Filosofía por la Universidad del Valle. Profesor de tiempo completo de la licenciatura en Filosofía de la Fundación Universitaria Católica Lumen Gentium. Correo electrónico: hescobar@unicatolica.edu.co
} 


\section{La génesis de la conciencia tecnocrática}

$\mathrm{Al}$ inicio de su ensayo Ciencia y técnica como "ideología", J. Habermas (1994) alude al concepto de racionalidad y racionalización a partir de la definición planteada por M. Weber. Para Habermas, Weber introduce el concepto de racionalidad para caracterizar "la forma de la actividad económica capitalista, del tráfico social regido por el derecho privado burgués, y de la dominación burocrática. 'Racionalización' significa en primer lugar, la ampliación de criterios de la decisión racional" (Habermas, 1994, p. 53). En segundo lugar, también significa "la industrialización del trabajo social, con la consecuencia de que los criterios de la acción instrumental penetran también en otros ámbitos de la vida (urbanización de las formas de existencia, tecnificación del tráfico social y de la comunicación)" (Habermas, 1994, p. 53). Así, en los dos casos se trata de la racionalización, de la implantación de un tipo de racionalidad, es decir, de un tipo de acción que es la racional con respecto a fines: en primer lugar se trata de la elección entre posibles alternativas, esto es, acción estratégica; y en el segundo caso se trata de una implantación que afecta la organización de los medios, esto es, acción instrumental. De manera que,

[...] la progresiva "racionalización" de la sociedad depende de la institucionalización del progreso científico y técnico. En la medida en que la ciencia y la técnica penetran en los ámbitos institucionales de la sociedad, trasformando de este modo a las instituciones mismas, empiezan a desmoronarse las viejas legitimaciones. La secularización y el "desencantamiento" de las cosmovisiones, con la perdida que ello implica de su capacidad de orientar la acción, y de la tradición cultural en su conjunto, son la otra cara de la creciente "racionalidad" de la acción social. (Habermas, 1994, pp. 53-54)

En el análisis que desarrolla Marcuse sobre el concepto de racionalidad formal del cual,

Weber extrae tanto de la acción racional del empresario capitalista y del obrero industrial como la de la persona jurídica abstracta y del funcionario moderno, y que asocia tanto con criterios de la ciencia como de la técnica, tiene implicaciones que son de contenido (Habermas, 1994, p. 54)

Marcuse está convencido -dice Habermasque lo que...

Weber llamaba como "racionalización", no se implanta a la "racionalidad" en tanto que tal, sino que en nombre de la racionalidad lo que se impone es una determinada forma de oculto dominio político. Como la racionalidad de este tipo (en tanto que instrumental y/o estratégica) solo se refiere a la correcta elección entre estrategias, a la adecuada utilización de tecnologías y a la pertinente instauración de sistemas (en situaciones dadas para fines dados), lo que en realidad hace es sustraer la trama social global de intereses en la que se eligen estrategias, se utilizan tecnologías y se instauran sistemas a una reflexión y reconstrucción racionales. Aparte de eso, esa racionalidad [continúa Habermas] solo se refiere a las situaciones de empleo posible de la técnica y exige por ello un tipo de acción que implica dominio, ya sea sobre la naturaleza o sobre la sociedad. La acción racional con respecto a fines es, por su estructura misma, ejercicio de controles. (Habermas, 1994, p. 55).

De esto se sigue entonces que,

[...] la "racionalización" de la vida según los criterios de esta racionalidad viene a significar la institucionalización de un dominio que se hace ya irreconocible como dominio político: la razón técnica de un sistema social de acción racional con respecto a fines no se desprende de su contenido político. (Habermas, 1994, p. 55)

Para Marcuse, la razón técnica se convierte en pura ideología:

El concepto de razón técnica es, quizás, él mismo, bastante ideológico. No es solamente la aplicación que de ella se hace, sino que la misma técnica es dominación -sobre la naturaleza y los hombres-, una dominación metódica, científica, calculada, previsible. Los fines y los intereses particulares de la dominación no son "adicionales" o dictados a la técnica desde arriba. Ellos entran en la construcción del mismo sistema técnico. Pues la técnica es un proyecto social e histórico. La sociedad proyecta allí lo que ella y sus intereses dominantes deciden hacer de los hombres y de las cosas. Los fines de la dominación son "materiales" y pertenecen a la forma de la razón técnica. (Marcuse, 1969, pp. 33 -34) 


\section{Ya Marcuse enunció en otro contexto}

[...] había llamado la atención sobre el peculiar fenómeno de que en las sociedades capitalistas industriales avanzadas el dominio tiende a perder su carácter explotador y opresor y a tornarse "racional", sin que por ello desaparezca el dominio político: "el dominio está ahora condicionado por la capacidad y el interés en mantener el aparato en su conjunto y ampliarlo". (Marcuse, 1969a, p. 56)

En este sentido, Marcuse observó en el fenómeno de la represión ${ }^{3}$ bajo el capitalismo tardío "la intensificación del sometimiento de los individuos al inmenso aparato de producción y distribución, en la desprivatización del tiempo libre, en la casi irresoluble fusión de trabajo social productivo y destructivo" (Marcuse, 1957, p. 56). Así,

[...] esta represión puede desaparecer de la conciencia de la población, ya que la legitimación del dominio ha adquirido un carácter distinto: ahora apela a "la creciente productividad y creciente dominación de la naturaleza, que también proporcionan a los individuos una vida más confortable". (Marcuse, 1957, p. 56)

Tal como lo expresa con más detalle en $E l$ hombre unidimensional:

Y es aquí donde la llamada nivelación de las distinciones de clase revela su función ideológica. Si el trabajador y su jefe se divierten con el mismo programa de televisión y visitan los mismos lugares de recreo, si la mecanógrafa se viste tan elegantemente como la hija de su jefe, si el negro tiene un Cadillac, si todos leen el mismo periódico, esta asimilación indica, no la desaparición de las clases, sino la medida en que las necesidades y satisfacciones que sirven para la preservación del "sistema establecido" son compartidas por la población subyacente. (Marcuse, 1985, p. 38)

\footnotetext{
3 "Sabido es que, según Freud, la historia del hombre es la historia de su represión; los instintos deben ser desviados si la civilización quiere constituirse. Tal desviación produce un cambio en la naturaleza humana. El sujeto acaba sustituyendo el placer temporal por otro placer restringido pero seguro. En contra de este autor, Marcuse afirma que el principio de realidad provoca un cambio sustancial en el principio del placer; bajo el dominio de aquél, el hombre queda ligado a una racionalidad que le es impuesta por una sociedad que transustancia sus necesidades originales. [...] La represión es solo un proceso histórico convertido en naturaleza en interés de una forma específica de la cultura: aquella que se instaura como poder". (López Sáenz, 1988, p. 87).
}

\section{De esta forma vemos como:}

[...] la "racionalidad", en el sentido de Max Weber muestra aquí su doble rostro: ya no es solo la instancia crítica del estado de las fuerzas productivas, ante el que pudiera quedar desenmascarada la represión [...] sino que es al mismo tiempo un criterio apologético en el que esas mismas relaciones de producción pueden ser también justificadas como un marco institucional funcionalmente necesario. Así a medida que la "racionalidad" se muestra más integrada a los mecanismos de la producción técnica e industrial queda al mismo tiempo "neutralizada como instrumento de la crítica y rebajada a mero correctivo dentro del sistema”. (Habermas, 1994, p. 57)

De modo que cuando la realidad social se desajusta un poco de los instrumentos conceptuales del universo de controles productivos, se suele decir -en un lenguaje operativo propio de especialistas y tecnócratas- que a lo sumo la sociedad está "mal programada". Comenta Habermas que,

En la etapa del desarrollo científico y técnico las fuerzas productivas parecen entrar, pues, en una nueva constelación con las relaciones de producción: ya no operan en favor de la ilustración como fundamento de la crítica de las legitimaciones vigentes, sino que se convierten en las mismas en base de la legitimación. Y esto es lo que Marcuse considera históricamente nuevo. (Habermas, 1994, p. 57)

Una tesis que también amplía en El hombre unidimensional:

De nuevo nos encontramos ante uno de los aspectos más perturbadores de la civilización industrial avanzada: el carácter racional de su irracionalidad. Su productividad y eficiencia, su capacidad de incrementar y difundir las comodidades, de convertir lo superfluo en necesidad y la destrucción en construcción, el grado en que esta civilización transforma el mundo-objeto en extensión de la mente y el cuerpo del hombre hace cuestionable hasta la noción misma de alienación. La gente se reconoce en sus mercancías; encuentra su alma en su automóvil, en su aparato de alta fidelidad, su casa, su equipo de cocina. El mecanismo que une el individuo a su sociedad ha cambiado, y el control social se ha incrustado en las nuevas necesidades que ha producido. Las formas predominantes de control social son tecnológicas en un nuevo sentido. Es claro que la estructura 
técnica y la eficacia del aparato productivo y destructivo han sido instrumentos decisivos para sujetar la población a la división del trabajo establecida a lo largo de la época moderna. [...] en la época contemporánea, los controles tecnológicos parecen ser la misma encarnación de la razón en beneficio de todos los grupos e intereses sociales, hasta tal punto que toda contradicción parece irracional y toda oposición imposible. (Marcuse, 1985, p. 39)

Así las cosas, vemos que:

[...] hoy la dominación se perpetúa y amplía no solo por medio de la tecnología, sino como tecnología; y esta proporciona la gran legitimación a un poder político expansivo que engulle todos los ámbitos de la cultura. En este universo la tecnología proporciona también la gran racionalización de la falta de libertad del hombre y demuestra la imposibilidad técnica de la realización de la autonomía, de la capacidad de decisión sobre la propia vida. (Habermas, 1994, p. 58)

Por consiguiente, esta "ausencia de libertad no aparece ni como irracional ni como política, sino más bien, como sometimiento a un aparato técnico que hace más cómoda la vida y eleva la productividad del trabajo" (Habermas, 1994, p. 58). La racionalidad tecnológica, en lugar de eliminar el trabajo enajenado, "respalda la legalidad del dominio" (Habermas, 1994, p. 58). En este aspecto se concreta la posibilidad de un horizonte instrumentalista de la razón que se abre a una sociedad totalitaria de base racional. Tal racionalidad tecnológica es la que permite la conformación o constitución de una nueva ideología, esto es, de una conciencia tecnocrática resultado del proceso histórico de racionalización, es decir, del tránsito histórico de una sociedad tradicional a una sociedad modernizada. Tal nueva ideología convierte el progreso científico-técnico en fundamento de legitimación del capitalismo avanzado.

No obstante, esta nueva forma de legitimación ha perdido la vieja forma de ideología en el sentido marxiano del término: ya no se trata meramente de una falsa conciencia de la realidad como podría haber sido la religión en las sociedades tradicionales, por el contrario, en las sociedades modernas del capitalismo tardío son la ciencia y la técnica las que sirven a una legitimación ideológica. De esta forma,
[...] en otro tiempo era el poder social el que subyacía de forma inmediata a la relación entre capitalistas y trabajadores; hoy son las condiciones estructurales las que definen de antemano las tareas del mantenimiento del sistema; a saber: la forma en términos de economía privada de la revaloración del capital y una forma política de la distribución de las compensaciones sociales que asegura el asentimiento de las masas. (Habermas, 1994, pp. 97-98)

Veamos rápidamente en qué aspectos se distinguen la nueva ideología de la vieja ideología.

En primer lugar, dice Habermas que

[...] la conciencia tecnocrática no puede basarse en una represión colectiva de la misma forma que lo hacían las viejas ideologías. La lealtad de las masas solo puede obtenerse por medio de compensaciones destinadas a la satisfacción de necesidades privatizadas. (Habermas, 1994, p. 98)

Esto es, en la creación y búsqueda de satisfacción de nuevas necesidades que lleven a la población a participar del sistema como consumidores. No en vano, por ejemplo, la "ley de obsolescencia programada" ${ }^{”}$ relacionada con la vida útil de los aparatos electrónicos constituye una forma de perpetuar el dominio sobre la conciencia del consumidor.

En segundo lugar, y-tal vez el núcleo ideológico de la conciencia tecnocrática- se encuentra la eliminación de la diferencia entre práctica y técnica. Así, según Habermas, la conciencia tecnocrática "abole el sistema de referencia de interacción en el medio del lenguaje ordinario -propio del mundo de la vida - sistema en el que el dominio y la ideología surgen bajo condiciones de una distorsión de la comunicación” (Habermas, 1994, p. 99). Ello conlleva una especie de fenómeno de "despolitización de la masa de la población”, fenómeno legitimado a su vez, por la misma dinámica de la conciencia tecnocrática.

La actividad política que había sido la expresión práctica de la voluntad general es sustituida y

4 Esta actitud estimula positivamente la demanda al alentar a los consumidores a comprar nuevos productos de modo artificialmente acelerado si desean seguirlos utilizando. 
dejada hoy en manos de especialistas o tecnócratas que trazan las directrices políticas de una sociedad teniendo en cuenta criterios de eficacia y mayor productividad: es el horizonte racional de la administración tecnológica total. En este aspecto, la conciencia tecnocrática erosiona una de las condiciones fundamentales de nuestra existencia cultural: al "lenguaje, o más exactamente, a una forma de socialización e individuación determinadas por la comunicación en el medio del lenguaje ordinario" (Habermas, 1994, p. 99). Vale la pena examinar más de cerca este fenómeno.

A mitad del siglo xIx -comenta Habermas- la forma de producción capitalista se había impuesto en Inglaterra y en Francia hasta el punto que Marx podía reconocer históricamente el marco institucional de la sociedad en las relaciones de producción y al mismo tiempo podía criticar el fundamento ideológico que encubría tales relaciones de producción. En contraste con lo anterior, Weber elabora un concepto formal de razón que, si bien es histórico, tiende a una "cuantificación y abstracción de todas las particularidades, lo que hace posible la eficacia universal y previsible del aparato capitalista" (Marcuse, 1969, p.12). Para Weber los elementos característicos que constituyen la razón eran los siguientes:

1. Matematización progresiva de toda experiencia y de todo conocimiento, que, a partir de sus espectaculares éxitos en las ciencias naturales, se orienta a la conquista de las ciencias sociales y por último a la del propio modo de vida [cuantificación universal]

2. Insistencia en la necesidad de la experiencia y de las pruebas racionales tanto en la organización de la ciencia como en la de la vida.

3. Constitución y consolidación de una organización universal y especializada de funcionarios, que tiende hacia un control de toda nuestra existencia, al cual sería absolutamente imposible sustraerse. (Marcuse, 1969, p. 11)
Este último elemento -comenta Marcuse- era para Weber el resultado crucial de todo el proceso. La definición que él da efectúa la transición desde la razón práctica hacia la forma histórica de la razón. El concepto de ratio en Weber -con o a causa de su abstracción- contenía inicialmente una conciencia de su especificidad histórica. En el curso del análisis de Weber, esta conciencia se debilita para finalmente abdicar de toda posición decisiva. En su sociología, la racionalidad formal se convierte -y de manera indisociable- en la racionalidad capitalista: ella aparece como una disciplina sistemática aplicada sobre el irracional "deseo de ganar" y su formulación característica llega a ser "el ascetismo secular". En esta "disciplina", la razón occidental se convierte en la razón económica del capitalismo, la incitación a la ganancia siempre renovada en la continuación racional de la empresa capitalista.

La racionalidad llega a ser la condición de la rentabilidad, que a su vez está orientada para transformarse en un cálculo sistemático, metódico, el "balance" (Marcuse, 1969, p. 11). Así, básicamente lo que Marcuse critica a Weber es que sin prestar atención a los análisis históricos de la sociedad liberal elaborados por Marx, este se atiene a un concepto abstracto de "racionalización" que no desvela, sino que encubre la dominación de clase que ejerce el capitalismo tardío, el cual se legitima a través de la conciencia tecnocrática.

De modo que esta es precisamente - a juicio de Habermas- la tesis fundamental de Marcuse: "que la ciencia y la técnica cumplen también hoy funciones de legitimación del dominio [lo cual] nos proporciona la clave para analizar esa nueva constelación" (Habermas, 1994, p. 81). Esta constelación de fenómenos sociales tiene como rasgo representativo -como ya hemos señalado más arriba- el desmoronamiento de la vieja ideología, en la que "el dominio político requiere una nueva legitimación” (Habermas ,1994, p. 83). En efecto, el poder se ejerce indirectamente a través de procesos de intercambio, controlados a su vez por medio de consorcios financieros privados y la 
administración burocrática del Estado, de manera que todo aquello que atañe a la esfera de la política está encomendada a labor de expertos que deciden por encima de las reales aspiraciones y necesidades de los propios ciudadanos:

La dominación burocrática es inseparable de la industrialización avanzada. Ella impone la eficacia perfeccionada de la empresa individual sobre la sociedad que forma un todo. Es éste [sic] el tipo de dominación más formalmente racional, gracias a su "precisión, su estabilidad, la exigencia de su disciplina y la confianza que se le puede otorgar; a saber, la posibilidad, para quienes están al frente de ella, de calcularla”; y es todo esto, porque es "dominación por el saber", un saber fijo, calculable, que corresponde a los expertos. En realidad, es el aparato el que domina, ya que la dominación del aparato a través del saber de los expertos sólo [sic] es posible cuando está completamente adaptado a sus necesidades y a sus posibilidades técnicas. En consecuencia, el control del aparato "sólo [sic] es posible en menor medida, para los no especialistas". "El funcionario permanente y especialista tiene más oportunidades de mantenerse a largo plazo que el ministro, que no es especializado". (Marcuse, 1969, p. 25)

\section{Es así que para Habermas,}

[...] la dominación en términos de democracia formal, propia de los sistemas del capitalismo regulado por el Estado, se ve ante una necesidad de legitimación, que ya no puede ser resuelta recurriendo a legitimaciones preburguesas. De ahí que la ideología del libre cambio quede reemplazada por un programa sustitutorio que se centra en las consecuencias sociales no de la institución del mercado, sino de una actividad estatal que compensa las disfunciones del libre intercambio. (Habermas, 1994, p. 83)

Es decir,

[Al asegurar] un mínimo de bienestar, estabilidad en los puestos de trabajo y de estabilidad de los ingresos, este programa sustitutorio obliga al sistema de dominio a mantener las condiciones de estabilidad de un sistema global que garantiza la seguridad social y las oportunidades de promoción personal y a prevenir los riesgos del crecimiento. (Habermas, 1994, p. 84)

A través del sistema de compensaciones y nivelaciones sociales se logra vincular de esta forma "el asentimiento de la masa de la población". Se obtiene -en apariencia- el "estatus de legitimidad" de los integrantes de la totalidad social. Se apunta que es en apariencia porque el programa sustitutorio puesto en marcha por una élite de expertos "excluye las cuestiones prácticas y con ello la discusión sobre criterios que solo podrían ser materia de una formación democrática de la voluntad política. La solución de tareas técnicas no se refiere a la discusión pública, ya que lo único que esta haría sería problematizar las condiciones marginales del sistema dentro de las cuales las tareas de la actividad estatal se presentan como técnicas" (Habermas, 1994, p. 85). Por ello, señala Habermas que:

La nueva política del intervencionismo estatal exige por eso una despolitización de la masa de la población. Y en la medida en que quedan excluidas las cuestiones prácticas, queda también sin funciones la opinión pública. (Habermas, 1994, p. 85)

En cualquier caso, Habermas considera que:

[...] el marco institucional de la sociedad sigue siendo todavía algo que no se identifica con los subsistemas de acción racional con respecto a fines. Su organización sigue siendo una cuestión de la práctica ligada a la comunicación, y no solamente a un problema técnico, aunque la técnica sea de cuño científico. (Habermas, 1994, p. 86)

\section{El tránsito de una racionalidad instrumental a una racionalidad comunicativa}

Ahora bien, para mostrar que la política es una actividad práctica ligada a la comunicación, Habermas reformula el concepto de racionalidad de Weber, al tiempo que también señala -en parte contra la tesis defendida por Marcuse- que solo existe un tipo de racionalidad, a saber, la razón instrumental. Para llevar esto a cabo, Habermas retoma la distinción hegeliana del periodo de Jena entre trabajo e interacción con el fin de matizar conceptualmente su postura frente a estos dos pensadores. 
Así, por trabajo o acción racional con respecto a fines, Habermas entiende que "o bien la acción instrumental o bien la elección instrumental se orienta por reglas técnicas que descansan sobre el saber empírico" (Habermas, 1994, p. 68).

[Tales] reglas implican en cada caso pronósticos sobre sucesos observables, ya sean físicos o sociales; estos pronósticos pueden resultar verdaderos o falsos. El comportamiento de la elección racional se orienta de acuerdo con estrategias que descansan en un saber analítico. (Habermas, 1994, p. 68)

Por consiguiente,

[...] la acción racional con respecto a fines realiza fines definidos bajo condiciones dadas. Pero mientras la acción organiza medios que resultan adecuados o inadecuados según criterios de un control eficiente de la realidad, la acción estratégica solamente depende de la valoración correcta de las alternativas de comportamiento posible, que solo puede obtenerse por medio de una deducción hecha con el auxilio de valores y máximas. (Habermas, 1994, p. 68)

Por otro lado, Habermas entiende por acción comunicativa una interacción simbólicamente mediada por normas

[...] intersubjetivamente vigentes que definen expectativas recíprocas de comportamiento y que tienen que ser entendidas y reconocidas, por lo menos por dos sujetos agentes. Las normas sociales vienen urgidas por sanciones. Su sentido se objetiva en la comunicación lingüística cotidiana. Mientras que la validez de las reglas técnicas y de las estrategias dependen de la validez de los enunciados empíricamente correctos, la validez de las normas sociales solo se funda en la intersubjetividad del acuerdo sobre intenciones y solo viene asegurada por el reconocimiento general de obligaciones. (Habermas, 1994, p. 69)

Ahora bien, cabe preguntarse ¿qué logra Habermas al introducir esta distinción entre trabajo e interacción si el trabajo también es de cierta forma, una mediación entre la conciencia y la naturaleza y por ello una interacción con el mundo real? No obstante, si adopta este enfoque se pierde precisamente la distinción que intenta resaltar Habermas para matizar el concepto de "racionalidad", el cual no se puede reducir - a su juicio- a mera acción instrumental asociada a la categoría de "trabajo"; la categoría de "interacción" estaría haciendo referencia a la acción comunicativa que es la racionalidad orientada a acuerdos en un horizonte intersubjetivo.

$\mathrm{Al}$ atenerse a esta diferenciación entre los dos tipos de acción es posible comprender la aclaración conceptual que lleva a cabo el joven Habermas a su maestro Marcuse: que el ejercicio de racionalidad no se reduce a mera acción instrumental, sino que también a través del ejercicio de la racionalidad, aparece la posibilidad de construir y contradecir argumentos con los cuales podamos llegar intersubjetivamente a consensos, así fuesen en el plano de la provisionalidad. Una exposición crítica de argumentos, al igual que el disenso es un ejercicio pleno de racionalidad. De modo que para Habermas, solo el concepto de acción comunicativa:

[...] presupone el lenguaje como un medio de entendimiento sin más abreviaturas, en que hablantes y oyentes se refieren, desde el horizonte pre-interpretado que su mundo de la vida representa, simultáneamente a algo en el mundo objetivo, en el mundo social y en el mundo subjetivo, para negociar definiciones de la situación que puedan ser compartidas por todos. Este concepto interpretativo de lenguaje es el que subyace a las distintas tentativas de pragmática formal. (Habermas, 1987a, pp.137-138)

Cabe precisar además que la acción comunicativa no se debe reducir meramente a entendimiento lingüistico, ya que el lenguaje es solamente el medio, el mecanismo de coordinación de la acción:

En realidad, el entendimiento lingüístico es sólo [sic] el mecanismo de coordinación de la acción, que ajusta los planes de acción y las actividades teleológicas de los participantes para que puedan constituir una interacción. (Habermas, 1987a, p. 138)

En este sentido, la interacción lingüística es la que permite la comunicación racional de las pretensiones de validez universalizables entre dos o más participantes en una discusión o situación que 
involucra diversos actores. Por ello, el concepto de racionalidad comunicativa:

[...] posee connotaciones que en última instancia se remontan a la experiencia central de la capacidad de aunar sin coacciones y de generar consenso que tiene un habla argumentativa en que diversos participantes superan la subjetividad inicial de sus respectivos puntos de vista y merced a una comunidad de convicciones racionalmente motivada se aseguran a la vez de la unidad del mundo objetivo y de la intersubjetividad del contexto en que desarrollan sus vidas. (Habermas, 1987a, p. 27)

Como se ve, Habermas elabora una teoría del lenguaje que tiene pretensión de universalidad. Una reflexión en la que "el lenguaje está al servicio de la coordinación social, salvando las barreras culturales y las creencias individuales o de grupos" (Fernández, 1997, p. 30). Así, al articular el concepto de lenguaje con el de sociedad, y este con el de mundo de la vida como horizonte de referencia, "se abre la posibilidad de una teoría del lenguaje que concilie la acción con la interpretación" (Fernández, 1997, p. 30).

Según Sergio Fernández, Habermas pretende que la noción de la racionalidad comunicativa "está contenida implícitamente en la estructura del habla humana como tal y que significa el estándar básico de la racionalidad que comparten los hablantes competentes al menos en las sociedades modernas" (Fernández, 1997, p. 30). En este sentido, se puede observar que el concepto de interacción social mediada por el lenguaje es uno de los elementos constitutivos de la acción comunicativa, ya que a través de la mediación lingüística se comprende la relación interna entre los requisitos de validez y el compromiso con respecto a dar y recibir argumentos, por ende se puede saber si el individuo está procediendo racionalmente.

El proceso de interacciones simbólicas no se evidencia solamente en una dimensión de relaciones lógicas entre proposiciones y acciones (coherencia) sino en el ámbito de las relaciones dialógicas entre diferentes hablantes. Lo anterior implica que "la racionalidad comunicativa es también una actitud racional específica que los individuos adoptan hacia otros y hacia sí mismos como una actitud de reconocimiento mutuo" (Fernández, 1997, p. 30).

La propuesta filosófica de Habermas se enfoca en un panorama de reconciliación de una modernidad que se halla descontenta consigo misma. En la modernidad es posible encontrar formas de convivencia en las que se da una relación satisfactoria entre autonomía y dependencia, sin por ello prescindir de las diferenciaciones que han hecho posible la vida moderna, tanto en el ámbito cultural como en el social y económico. En este sentido, el pensador alemán defiende "la idea de que es posible una vida digna en una comunidad que no plantea el carácter dudoso de comunidades sustanciales vueltas hacia el pasado" (Habermas, 1987a, pp. 170-171).

Habermas ha trabajado con dedicación en aras de "desarrollar una teoría de la sociedad con intención práctica" (Habermas, 1987b, p. 13). Su pretensión reflexiva consiste en fundamentar las bases de dicha teoría de tal forma que le permita contribuir a la realización de las metas emancipatorias de la modernidad ilustrada. Esta propuesta filosófica no solo se relaciona con la tradición ilustrada, sino también con la tradición crítica del marxismo y, en concreto, con la crítica a las ideologías de la Escuela de Fráncfort. Habermas rehabilita el proyecto ilustrado que se concebía como un programa de emancipación, es decir, como un ideal enfocado en la libertad y en la justicia. Y puesto que emanciparse -como lo concebía Kant- significa tener la capacidad para decidir por uno mismo, ello implica un grado de autonomía en la que la que es de carácter personal marca la orientación del actuar moral. En el plano político, "el punto de orientación normativa sería el autogobierno, y el objetivo, la configuración de una sociedad libre de dominación" (Velasco, 2013, p. 29).

Resulta palmario resaltar que la teoría crítica se concebía sí misma, no solo como marco teórico, sino también como un agujón crítico y motor utópico, tareas con las que Habermas se identifica. 
De hecho, esta influencia vendría de la primera generación de la Escuela de Fráncfort, la cual mantuvo un vínculo heterodoxo con el marxismo clásico, una tendencia que posteriormente se hizo aún más evidente. En efecto, la Escuela de Fráncfort tendía a considerar el marxismo, no como una norma a la que había que adherirse fielmente, sino como "un punto de partida y una ayuda para el análisis y la crítica de las relaciones sociales y el entramado cultural" (Velasco, 2013, p. 30).

En la obra de Habermas se conserva el impulso emancipatorio que recorre la obra de Marx, como culminación de una tradición ilustrada; en palabras suyas, sus "intereses teóricos han estado constantemente determinados por aquellos problemas filosóficos y socio-teóricos que surgen del movimiento intelectual que va de Kant a Marx" (Habermas, 1987a, p. 183). Así y conservando el motivo inicial de la teoría crítica, Habermas ha buscado alcanzar un concepto ampliado de razón que permita superar los planteamientos diferentes y parciales sobre la racionalidad, puestos en escena en la época moderna. De esta manera, se pueden señalar como puntos de continuidad entre el pensamiento de Habermas y la primera Escuela de Fráncfort: a) la idea de la teoría crítica enfocada hacia la "autoemancipación de los seres humanos" (Velasco, 2013, p. 38); b) la crítica al carácter ambiguo de la Ilustración y el proceso de racionalización movilizado por la modernidad; c) la crítica a los fundamentos epistemológicos de la sociología positivista; y d) el carácter interdisciplinar de la teoría crítica de la sociedad.

Entre los puntos en los cuales divergen los planteamientos de Habermas y la primera generación de la Escuela de Fráncfort habría que destacar: a) la pretensión de Habermas de desarrollar una "gran teoría social", mientras que la escuela de Fráncfort se resistió a elaborar una teoría desde un sistema conceptual único; b) Habermas fundamenta la racionalidad bajo el trasfondo de un contexto intersubjetivo del lenguaje, al contrario de Adorno y Horkheimer que se movían epistemológicamente bajo el enfoque de la filosofía de la conciencia o de la subjetividad; c) la propuesta de Habermas es constructiva o positiva, mientras que la reflexión que planteaba la primera generación de la Escuela de Fráncfort es una dialéctica negativa que deriva en una especie de nihilismo.

Por lo anterior, el proyecto filosófico y social de Habermas tiene la intención de mostrar cómo su idea de racionalidad comunicativa ya hace parte de las principales instituciones de la democracia liberal, de tal modo que resulte posible realizar una crítica de las estructuras y prácticas en esas sociedades. Por esta razón, Norbert Bolz señala que con Habermas "la teoría crítica pierde su tono desesperanzado y se muta en filosofía normativa" (Bolz, 2003, p. 52). En otros términos, la dialéctica negativa se convierte en teoría constructiva de las ideas, la función crítica se sustituye con una función propositiva (Velasco, 2013, p. 39).

La teoría de la acción comunicativa tiene su origen en el concepto de Georg Herbert Mead sobre la interacción mediada por símbolos ${ }^{5}$. A través de la acción comunicativa se intenta rescatar lo salvable de la razón práctica. De esta forma, mediante el elemento comunicativo de la razón Habermas establece una revisión de la teoría crítica para sacarla de sus problemas, como el esteticismo de Adorno o el recurso final a la trascendencia de Horkheimer. En este sentido, Albrecht Wellmer señala que Habermas ha logrado traducir el proyecto de "una teoría crítica de la sociedad desde el marco conceptual de la

5 "El Interaccionismo simbólico es una corriente de pensamiento propia de la sociología, la antropología y la psicología, definida a partir del primer tercio del siglo xx. La premisa elemental es entender a las personas como seres sociales que viven en interacción con el resto, y ver en los procesos de interacción el peso relevante en la configuración del significado para el individuo y su consecuente contribución a su personalidad. [...] El interaccionismo simbólico entiende que la interacción se lleva a cabo mediante el intercambio de actos simbólicos como son los gestos, las palabras, la entonación o la expresión de la cara. Ese manejo de símbolos en nuestra comunicación, la dota de significado. A su vez permite transmitir información y expresar ideas, entender las experiencias propias y la de los otros, así como compartir sentimientos y entender [los] de los demás. El interaccionismo simbólico pone en relieve que para entender al ser humano lo importante no es la conducta en sí, sino el significado que esta tiene. La intención con la que actúa el emisor y la interpretación que le da a ese mismo acto el receptor, forman el significado de la conducta para cada parte de la interacción." (Cubillas Fontana, 2014/2015). 
filosofía de la conciencia, adaptada a un modelo de sujeto-objeto de cognición y acción, al marco conceptual de una teoría del lenguaje y la acción comunicativa" (Wellmer, 1994 p. 89). Este cambio de perspectiva le posibilitó modificar las categorías marxistas de trabajo y alienación por "la tensión entre los supuestos comunicativos del mundo de la vida y los imperativos funcionales de autorregulación propios del sistema social" (Velasco, 2013, p. 47).

La concepción de la racionalidad práctica abordada por Habermas recoge múltiples tradiciones y disciplinas, las cuales el pensador alemán sabe encajar como si fueran piezas de un único rompecabezas. El concepto de racionalidad tiene como base lo analizado por los teóricos de la acción social como Durkheim, Weber, Mead, Parsons y Marx; resulta clave el papel del giro lingüístico de la filosofía contemporánea, en especial el enfoque pragmático del segundo Wittgenstein y la filosofía del lenguaje que se desprende de la teoría de los actos de habla de Austin y Searle. Bajo esta mirada, la racionalidad práctica se interpreta -a la luz de la racionalidad comunicativa- como "una razón ya inscrita en el propio proceso cotidiano de la comunicación lingüística" (Velasco, 2013, p. 47).

Tanto la filosofía griega como la lingüística tradicional concibieron el lenguaje a partir de una función denotativa o informativa, es decir que para ellos, se basa en enunciados descriptivos de valor de verdad, tales como afirmaciones, descripciones, narraciones, suposiciones. No obstante, así como existen enunciados descriptivos, hay otro tipo de enunciados llamados performativos, que estarían más asociados a la realización de una acción. Los actos de habla "no describen la realidad, sino que la generan o la hacen" (Velasco, 2013, p. 48). Ejemplos de ello son: promesas, insultos, saludos y autorizaciones u órdenes. Estos actos de habla no son ni verdaderos ni falsos, "pueden ir o no seguid[o]s de un efecto, en función de cómo 1[o]s interpreten los que 1[o]s entienden, los que 1[o]s emiten y quienes sean sus destinatarios" (Velasco, 2013, p. 48). Tienen, a juicio de Austin, "sus propios criterios de validez: carecen de valor de verdad, pero pueden ser evaluad[o]s por su acierto o fortuna en la consecución del efecto buscado por el hablante en su emisión" (Velasco, 2013, p. 48).

A partir de las consideraciones anteriores es posible definir algunos rasgos de los actos de habla. Estos últimos son unidades de sentido que se realizan al ejecutar un acto comunicativo, así, al participar de un acto de habla "se dice a la vez que se hace" (Habermas, 1987a, p. 116). De acuerdo con Austin, los efectos producidos por un acto de habla poseen tres dimensiones que pueden estar reflejados o no en cada emisión:

a. El acto locucionario: es el acto de hablar y decir algo. Es la manifestación verbal en cualquier acto de comunicación.

b. El acto ilocucionario: es el acto que llevamos a cabo o que se da a entender cuando se dice algo, es decir la acción que un hablante realiza al expresar algo (por ejemplo, ordenar, preguntar, prometer o emitir un juicio).

c. El acto perlocucionario: es el efecto producido en el mundo al decir algo (por ejemplo, tranquilizar o atemorizar a alguien).

Para Habermas, los actos de habla en su doble estructuración proposicional e ilocucionaria le permiten a los interlocutores moverse en el ámbito de la interdisciplinariedad "en el que hablan entre sí, y en el de los objetos sobre los que se entienden" (Velasco, 2013, p. 48). De este modo, un acto ilocucionario es exitoso cuando de manera cooperativa existe una interacción entre hablante y oyente, ya que suponen que los participantes asumen compromisos que "vinculan tanto al emisor como al destinatario de la comunicación" (Velasco, 2013, p. 49).

Esta doble estructura del lenguaje se hace evidente en un nivel interactivo y cognitivo, esto es, tanto en el entendimiento entre los hablantes como en el acuerdo sobre la cosa que se discute. La perspectiva fundamental que los actos de habla 
introducen es que -a juicio de Habermas- los participantes en una discusión terminan -de alguna manera- vinculada no solo en el nivel discursivo, sino además, en el nivel de la acción. Es importante dejar por sentado además, que en la teoría de la acción comunicativa un "enunciado no es verdadero por que corresponda a un determinado estado de cosas, ni simplemente porque resulte coherente con otros enunciados; lo es porque a lo largo del proceso comunicativo llega a ser aceptado como justificado bajo determinadas condiciones" (Velasco, 2013, p. 50).

Las condiciones se estarían refiriendo a ciertas reglas, como la no coacción dentro del proceso argumentativo, la igualdad de derechos y deberes de la argumentación, la claridad en la presentación de razones. Por ello, una regla de juego fundamental radica en exponer todo tipo de razones hasta que se tengan por válidas como las mejores, de acuerdo con el conocimiento disponible en un momento determinado. En efecto, será necesario apelar a razones justificatorias que apoyen una pretensión de verdad, la cual se ha de entender en la práctica cotidiana como "aseverabilidad justificada mediante razones” (Habermas, 2002a, p. 276).

$\mathrm{Al}$ respecto, si se desea ilustrar de manera radical el planteamiento de Habermas se podría tomar por ejemplo la decisión de la administración Bush de ocupar Irak militarmente en el 2003 por medio de la resolución 1441 en la que se señaló que el gobierno de Saddam Hussein fue:

[...] un régimen que desarrolló y usó armas de destrucción masiva, que albergó y apoyó el desarrollo de grupos terroristas, que cometió indignantes violaciones a los derechos humanos y desafió las demandas de las Naciones Unidas y el mundo entero. (Departamento de Estado, Agencia de Relaciones Públicas, 2003, citado en Wikipedia, s.f.a)

En este sentido, se tuvo que justificar dicha campaña militar ante la opinión pública norteamericana y el escenario político internacional mediante unas razones. Cuando el argumento principal de la resolución 1441 se basó en la producción de armas de destrucción masiva por parte del régimen de Hussein mostró ciertas inconsistencias, la administración Bush argumentó entonces que había un vínculo entre Hussein y Al Qaeda, esto con el fin de encontrar una legitimidad en la opinión pública. Aun cuando todas estas razones se basaron en una racionalidad estratégica o en una campaña organizada de manipulación (Ekaizer, 2006), estuvieron enfocadas en una finalidad específica: la persuasión de la opinión para legitimar una acción bélica. El poder justificar acciones políticas y militares discursivamente mediante la exposición de los mejores argumentos.

Como se ve, el lenguaje juega un papel relevante en la reflexión planteada por Habermas, tanto así que en este punto coincide con Tugendhat, quien sostiene que "los seres humanos debido a su lenguaje, poseen la capacidad de deliberar, y todo el que delibera pregunta por razones" (Tugendhat, 2002, p. 143). Efectivamente, la acción comunicativa se convierte en sinónimo de racionalidad al tratar de dar cuenta de las mejores razones a través del diálogo, esto confirmaría uno de los postulados más destacados del pensamiento filosófico de Habermas: "la afirmación de que el concepto racionalidad presupone la existencia de la comunicación lingüística o, dicho de otro modo, la razón es de por sí ya razón comunicativa" (Velasco, 2013, p. 51).

Al estar la racionalidad conformada dialógicamente, el concepto de razón no sería meramente instrumental o teleológico bajo el paradigma de la conciencia, como lo definieron Horkheimer y Adorno (2009) en La dialéctica de la Ilustración, sino que se abre a otros tipos de racionalidad. Quien lleva a cabo un acto de habla ofrece a sus interlocutores una posibilidad de entendimiento que "se da en su propia subjetividad, en el mundo objetivo, o en el mundo social" (Velasco, 2013, p. 53).

La estructura lingüística revela varios niveles de realidad: las tres funciones del lenguaje (emotiva, cognitiva y apelativa), y las respectivas pretensiones de validez que van a constituir una alusión 
con las vivencias privadas, la naturaleza y la intersubjetividad. De esta forma, las respectivas formas de acción, funciones del lenguaje, pretensión de validez y referencias a los distintos mundos se pueden representar de la siguiente manera en la tabla 1:

Tabla 1. Tipos de racionalidad

\begin{tabular}{|c|c|c|c|}
\hline Forma de acción & Función del lenguaje & $\begin{array}{l}\text { Pretensión } \\
\text { de validez }\end{array}$ & Referencia extralingüística \\
\hline Acción teleológica & Cognitiva o representativa & Verdad proposicional & Mundo objetivo \\
\hline Acción normativa & Apelativa o directiva & $\begin{array}{l}\text { Corrección o rectitud } \\
\text { normativa }\end{array}$ & Mundo social o intersubjetivo \\
\hline Acción dramatúrgica & Expresiva o emotiva & Veracidad o sinceridad & Mundo subjetivo \\
\hline Acción comunicativa & $\begin{array}{l}\text { Todas las funciones del } \\
\text { lenguaje }\end{array}$ & Entendimiento & $\begin{array}{l}\text { Referencia reflexiva a los } \\
\text { tres mundos }\end{array}$ \\
\hline
\end{tabular}

Fuente: Velasco (2013, p. 53)

Cabe anotar que la propuesta de Habermas no se orienta meramente a una caracterización lingüística, sino al desarrollo de una teoría de la acción social, en la que alude a la obra de Max Weber (y en parte también a Talcott Parsons), quien define acción social como "una acción en donde el sentido mentado por su sujeto o sujetos está referido a la conducta de otros, orientándose por ésta [sic] en su desarrollo" (Weber, 2012, p. 5). De esta forma, Habermas intenta responder a la pregunta: ¿cómo es posible la acción colectiva?

Las acciones en común que requieren de la cooperación de más de un individuo -como el baile de un grupo o la acción de dos hombres cortando un árbol- están basadas en un entendimiento mutuo, en un diálogo que, aunque puede ser mínimo o incluso implícito, necesita la mediación del lenguaje. No parece ser excesivo afirmar que Habermas complementa la reflexión weberiana de la acción social con el análisis de los actos de habla con la cual comprende las distintas formas de racionalización. Esto conduce a señalar que el primer modo de interacción social "es aquella en la que la acción viene coordinada por un empleo orientado a entenderse. A este tipo de acción es a lo que Habermas llama 'acción comunicativa" (Velasco, 2013, p. 55).
Luego de lo que se ha desarrollado en el presente escrito, se puede señalar que la teoría crítica de Habermas tiene un trasfondo socio-lingüístico basado en la teoría de la pragmática universal en la que defiende "la tesis de que el uso del lenguaje orientado al entendimiento es el uso original del mismo. Alcanzar un acuerdo o entendimiento entre las partes que participan en el proceso comunicativo es el telos inherente al lenguaje humano" (Velasco, 2013, p. 55). Para el filósofo alemán, los otros usos del lenguaje, como por ejemplo, el instrumental o el expresivo, serían subsidiarios del comunicativo. Lo cierto es que al valerse del lenguaje, "el individuo participa necesariamente de la perspectiva social y sale así de 'la lógica egocéntrica" (Habermas, 1990, p. 85). En otras palabras, para Habermas la comunicación tiene sentido cuando está orientada al entendimiento con el otro, situación que le exige a los interlocutores el cumplimiento de "las condiciones de racionalidad inmanentes a la acción comunicativa" (Habermas, 1987a, p. 506).

Con base en lo anterior es posible arribar al hecho de que toda acción lingüística es una acción orientada al entendimiento, que implica una acción social al comunicar y por ende, no se pueden excluir ciertas condiciones presentes en todo diálogo. Cuando varios interlocutores discuten un tema "se 
apoyan en un suelo en principio inamovible de presupuestos básicos no problematizados. Incluso el desacuerdo tendría lugar sobre un trasfondo de acuerdos tácitos" (Velasco, 2013, p. 55). Este ámbito de sedimentaciones culturales e ideas familiares es el mundo de la vida. Tal conjunto de saberes compartidos conforma una realidad en la que está inmerso el sujeto. Así, "en tanto que seres históricos y sociales, nos encontramos ya siempre en un mundo de la vida estructurado lingüisticamente" (Habermas, 2002b, p. 22).

Si bien la noción de entendimiento es un elemento central en la teoría de la acción comunicativa porque permite entender las razones de un consenso o un disenso, para Javier Muguerza tal noción adolece de una notoria ambigüedad (Muguerza, 1990, p. 288). Tanto en alemán (verständigung) como en español, la palabra entendimiento se refiere a dos asuntos diferentes: por una parte, se refiere a la idea de haber comprendido lo dicho, por otra parte, de estar de acuerdo con lo dicho (Velasco, 2013, p. 56). Si bien es verdad que la comprensión o el entendimiento de lo dicho es un requisito necesario para lograr un consenso sobre algún asunto, establecer un acuerdo solo porque se está de acuerdo con algo no es nada evidente. Por ejemplo, que se entiendan las "posibles razones" dadas a la opinión pública por las cuales la administración de Bush en el 2003 justificó una campaña de guerra preventiva contra Sadam Hussein y el terrorismo no implica necesariamente que se esté de acuerdo con la apropiación y explotación de las potencias extranjeras de los recursos nacionales y energéticos de Irak. Otra situación que ejemplifica, en materia de política real mucho más actual, es que no estar de acuerdo con algunas de las decisiones de la administración de Maduro no legitima la acción social de EE. UU. de emprender una ocupación militar en suelo venezolano.

\section{Conclusiones}

A través del concepto de razón instrumental Marcuse muestra el modo en el que el sistema económico impone un modelo de razón basado en el ideal de eficacia y mayor productividad, mediante el cual el individuo es visto como una pieza en el complejo mecanismo del sistema social. El papel de la participación política del individuo se ve erosionado, al igual que la opinión pública frente a la creciente influencia de los medios de comunicación -por un lado- y el papel de los expertos -por el otro-, los cuales contribuyen a legitimar un modelo social basado en la efectividad y el consumo.

En contraste con esta idea, en su propuesta de la teoría de la acción comunicativa Habermas pretende mostrar que la racionalidad no se limita a un solo tipo, es decir, a un tipo de racionalidad de medios y fines como la que caracteriza a la actividad científica y tecnológica. Por el contrario, Habermas amplía el horizonte de comprensión del concepto de razón: se pasa de una conciencia tecnocrática a una conciencia comunicativa. Para Habermas el ejercicio de la construcción de lo político no debe quedar reducido a la opinión de los expertos, sino que se debe caracterizar por la apertura a la participación e inclusión política de todos los sectores de la sociedad. Precisamente en la esfera de lo político es en la cual cobra sentido la acción comunicativa, pues a través de este modelo socio-lingüístico de la acción se da la posibilidad de establecer una mediación en el horizonte intersubjetivo con el objeto de discutir los problemas más acuciantes de nuestra sociedad y movilizar así a los participantes hacia una praxis comunicativa que permita confrontar y sintetizar otros puntos de vista que aporten dialógicamente a la posibilidad de transformación política de la totalidad social.

La teoría de la acción comunicativa publicada en 1981, expresa los esfuerzos de Habermas por reconstruir una teoría de la sociedad con intensión práctica. De esta forma, la obra se articula bajo tres grandes objetivos: 1) elaborar un concepto de racionalidad por fuera del paradigma de la filosofía de la conciencia o de la subjetividad; 2) establecer una concepción de lo social en dos niveles que logre referenciar el ámbito de los sistemas y el mundo 
de la vida; y por último, 3) desarrollar una teoría crítica de la modernidad que dé cuenta de sus patologías, de modo que permita depurar y rehabilitar el proyecto de la Ilustración.

Habermas analiza las temáticas mencionadas como:

[...] una combinación nada corriente de construcciones teoréticas y reconstrucciones históricas de las ideas de los clásicos de la teoría social. Los pensadores sobre los que Habermas discute-Marx, Weber, Durkheim, Mead, Lukács, Horkheimer, Adorno, Parsons- siguen en buena parte vivos. (McCarthy, 2002, p. 446)

En efecto, Habermas discute con estos pensadores como virtuales interlocutores en un diálogo con el fin de examinar las contribuciones de estos pensadores, al tiempo que también critica y supera sus debilidades, "pensando con ellos para ir más allá de ellos" (McCarthy, 2002, p. 446).

La respuesta de Habermas a los desafíos del paradigma de la conciencia contenidos en la primera generación de la Escuela de Fráncfort está impulsada por un giro explícito hacia el paradigma del lenguaje. Para el filósofo alemán la capacidad del ser humano para comunicarse tiene un trasfondo universal, "unas estructuras básicas y reglas fundamentales que todo sujeto domina al llegar a hablar una lengua" (McCarthy, 2002, p. 449).

Por otra parte, la competencia comunicativa no solo se refiere a la facultad de realizar oraciones sintácticamente correctas, ya que al hablar nos ponemos en relación con el mundo objetivo que nos rodea, con los demás y con nuestras intenciones y deseos. En cada uno de estos niveles estamos poniendo en marcha una serie de pretensiones de validez que quedan evidenciadas en el discurso. Estas pretensiones o argumentaciones están relacionadas con la verdad si están asociadas al mundo físico; o pretensiones relacionadas a la rectitud, adecuación de nuestro discurso con los valores y normas compartidos con el mundo de la vida; o pretensiones de autenticidad o sinceridad si están vinculados con nuestras intenciones y sentimientos. Estas pretensiones de validez o argumentaciones se pueden cuestionar, criticar, defender y revisar. De manera que al apelar a un argumento o justificar determinada posición ideológica, se hace uso de nuestra capacidad de dar razones al expresarlas racionalmente mediante un discurso, eso sería precisamente la acción comunicativa, una acción que nos permite llegar a un entendimiento de un determinado asunto:

[...] la racionalidad inmanente a la práctica comunicativa cotidiana remite pues a la práctica de la argumentación como instancia de apelación que hace posible continuar la acción comunicativa con otros medios cuando un desacuerdo ya no puede ser absorbido por las rutinas cotidianas y sin embargo, no se lo quiere decidir recurriendo al uso directo o estratégico de la fuerza. (Habermas, 1987a, pp. 37-38)

Como se puede apreciar, la apelación al uso directo de la fuerza como en el caso de un enfrentamiento bélico se debe justificar racionalmente para buscar un entendimiento o una legitimidad de la acción que se va a emprender. La mera apelación a la fuerza no es consistente puesto que esta pretensión de ocupación militar necesita ser justificada frente un auditorio o ante la opinión pública para poder legitimar un uso estratégico de los recursos. Quizás sea por esto que Habermas afirme que su propuesta "no debe entenderse como una teoría que proponga el consenso como criterio de verdad sino como una que, por medio de la justificación discursiva de las pretensiones de validez" (Bengoa Ruiz de Azúa, 1992, p.140), posibilita llegar a un entendimiento mutuo y racional sobre algún asunto.

\section{Referencias}

\section{Arendt, H. (1993/2016). La condición bumana (R. Gil} Novales, trad.). Barcelona. Paidós, Espasa Libros.

Bengoa Ruiz de Azúa, J. (1992). De Heidegger a Habermas. Barcelona: Herder.

Bolz, N. (2003). Habermas: el filósofo de la República federal. Revista de Occidente, (270), 51-58. 
Cubillas Fontana, I. (2014/2015). Interaccionismo simbólico. Revista Crimipedia. Recuperado de http://crimina.es/crimipedia/wpcontent/uploads/2015/05/InteraccionismoSimb\%C3\%B3lico.pdf

Ekaizer, E. (2006, mayo 4). "Bush manipuló para justificar la decisión ya adoptada de invadir Irak". Entrevista: Paul Pillar, jefe de la cia para Oriente próximo de 2000 a 2005. El País. Recuperado de https://elpais.com/diario/2006/05/04/ internacional/1146693618_850215.html

Fernández, S. (1997). Habermas y la teoría crítica de la sociedad. Legado y diferencias en teoría de la comunicación. Cinta de Moebio, (1), 27-41.

Habermas, J. (1987a). Teoría de la acción comunicativa (tomo I). Madrid: Taurus.

Habermas, J. (1987b). Teoría de la acción comunicativa (tomo II). Madrid: Tauros.

Habermas J. (1990). El pensamiento postmetafísico, Madrid: Taurus.

Habermas, J. (1994). Ciencia y técnica como "ideología". Madrid: Editorial Tecnos.

Habermas, J. (2002a). Israel o Atenas. Madrid: Trotta.

Habermas, J. (2002b). El futuro de la naturaleza bumana. Barcelona: Paidós.

Horkheimer, M., y Adorno, T. (2009). Dialéctica de la Ilustración. Madrid: Trotta.

López Sáenz, C. (1988). La crítica de la racionalidad tecnológica en Herbert Marcuse. Enrabonar,
(14), 81-93. Recuperado de http://www. raco.cat/index.php/enrahonar/article/ view/42680/90764

Marcuse, H. (1969). "Teoria de los instintos y libertad" en: psicoanálisis y política. Barcelona: Ediciones península.

Marcuse, H. (1969). Industrialización y capitalismo en Max Weber. En La sociedad industrial y el marxismo (pp 7-36.). Buenos Aires: Quintaria.

Marcuse, H. (1985). El hombre unidimensional. Barcelona: Planeta-De Agostini.

McCarthy, T. (2002). La teoría crítica de Jürgen Habermas. Madrid: Tecnos.

Muguerza. J. (1990). Desde la perplejidad. México: Fondo de Cultura Económica.

Tugendhat, E. (2002). Problemas, Barcelona: Gedisa.

Velasco, J. (2013). Habermas el uso público de la razón. Madrid: Alianza.

Weber, M. (2012). Economía y sociedad. México: Fondo de cultura económica.

Wellmer, A. (1994). Ética y diálogo. Barcelona: Anthropos.

Wikipedia (s. f. a). Justificación de la guerra de Irak. Wikipedia. Recuperado de https://es.wikipedia. org/wiki/Justificaci\%C3\%B3n_de_la_guerra_de_ Irak\#cite_note-winning-1 